\title{
PHYSIOLOGICAL AND PATHOPHYSIOLOGICAL CHANGES IN CHERNOBYL LIQUIDATORS LIVING IN HIGH
} ALTITUDE CONDITIONS

Article history:

Received 21 February 2019

Received in revised form 28 March 2019 Accepted 1 April 2019

\section{G.H. Khachatryan, A.G. Karapetyan}

Scientific Center of Radiation Medicine and Burns,

Armenia, Yerevan-0054, Davidashen, P/0 25, e-mail:ncrmio@web.am

KEYW ORDS - accident liquidators, hypoxia, morbidity, myocardial hypertrophy, functional status of organs and systems.

\section{INTRODUCTION}

It is known that the human body living in conditions of high mountains is under the constant exposure of the environmental factors, and, in case of prolonged exposure, these factors affect the physiological functions of the body, which in many cases leads to adaptation to the given conditions. Climatic factors, such as reduced atmospheric pressure, reduced oxygen partial pressure, temperature, humidity, high intensity of solar radiation, air ionization and other factors, affect the human body through the skin, lungs, sensory organs, causing different physiological shifts. [1-5].

As it has been stated by many authors $[6,7]$, in mountainous conditions, a complex of adaptive rearrangements take place, firstly associated with oxygen insufficiency. The main adaptive reactions to hypoxia in bighlanders are: somewhat increase in the respiration rate and lung ventilation; increased residual volume due to an increase of the quantity of functioning alveoles and increased perfusion of lung capillaries and rearrangement of tissue respiration $[8,9]$.

A number of authors $[4,10,11]$ have revealed significant differences in the status of the cardiovascular system, the function of external respiration and gas exchange, as well as the blood indices, between the inhabitants of lowland areas and indigenous highlanders.

The aim of the presented study has been to reveal the differences in morbidity, changes in the functional status of different organs and systems in liquidators living on the plains compared with the residents of the highland regions of Armenia.

\section{MATERIALS AND METHODS}

The survey involved 270 liquidators - residents of Armenia, living in the high mountains, who partici- pated in the work on eliminating the consequences of the Chernobyl NPP accident in 1986-1988. (I group). As a control group, 300 lowland liquidators were attracted (group II). All liquidators consisted in various age categories. The age of the liquidators during the period of the accident was between $20-55$ years (at the age of $20-30$ years $-12.6 \%$; $31-40$ years $-32.7 \%$; $40-50$ years $-38.5 \%$ and over 50 years $-16,2 \%$ ).

Liquidators were divided into 3 groups: the first one comprised of individuals with external radiation dose up to $10 \mathrm{cGy}(52.7 \%)$, the second - 10-20 cGy (41.7\%), and the third - above 20 cGy (5.6\%). Spirometric and immunological tests, general blood analysis (using complex unified tests) have been carried out in these liquidators. Immunological indices were studied such as white blood cells, E-rosetting (T-lymphocytes) and EAC-rosetting (B-lymphocytes): relative and absolute quantity, serum immunoglobulins $\mathrm{G}, \mathrm{A}, \mathrm{M}$, phagocytic activity and complement titer.

Using methods of system analysis, the following indices of lung function were analyzed: TiffeneauPinelli index (IND_TIF $=$ FEV1/VC), forced expiratory volume in 1 second (FEV1), the vital capacity of lungs (VC), peak expiratory flow (PEF) [12].

The changes in the cardiovascular system have also been analyzed: disturbances of the nutrition of the myocardium, arrhythmia, hypertrophy of the atria, conduction disturbances, valve sclerotic changes, heart failure.

The statistical analysis of the data has been carried out by means of a number of computer programs intended for statistical processing of digital data arrays. Electronic spreadsheet Microsoft Excel and specialized statistical packages Statsoft-7, SPSS-10, MedCalc, and StatGraphics Plus were used. Correlation, regression and dispersion factor analyses were carried out $[13,14]$.

\section{RESULTS}

Fig. 1 shows in dynamics the morbidity by the following systems: cardiovascular and chronic nonspecific lung diseases (CNSLD) in highlander and plainsmen liquidators.

As a result of many years ( 30 years) of research, it was found that regarding the respiratory system, the 

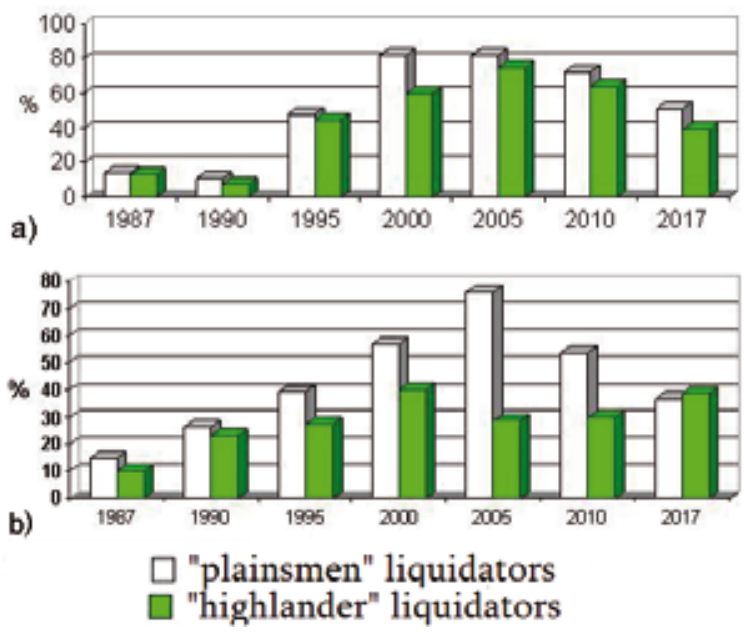

Fig. 1. Dynamics of the morbidity in "plainsmen" and "highlander" liquidators by the following systems: cardiovascular (a), CNSLD (b)

morbidity of liquidators living in high mountains was much lower throughout the whole period of the study (as compared to the plainsmen liquidators), which is obviously indicative of protective mechanisms in people who have long lived in hypoxic conditions. Indicators of lung function in the early post-accident period were also significantly different in the selected groups (table 1).
Using the dispersion factor analysis, the shares of the influence of the radiation factor were revealed on $\mathrm{VC}(50.57 \%)$ and FEV (34.5\%) in the early and VC (20.21\%) and FEV (24.13\%) in the long-term periods. Only at the end of the study did the morbidity rates for CNSLD in the highlander and plainsmen liquidators become almost equal, because of the gradual predominance of non-radiation factors such as age and smoking, that affect the morbidity for the respiratory tract. Thus, the results of dispersion factor analysis (Fig. 2) showed that the shares of the effects of smoking on lung function indicators (IND_TIF; FEV1 and VC) in the late period had increased by $1.5-3$ times.

Pulmonary hypertension and signs of right ventricular hypertrophy are considered to be the main adaptive changes in case of permanent residence in hypoxic conditions. The relationship of respiratory and cardiovascular disorders is particularly pronounced in the highlander liquidators. In permanent residents of the mountains, structural changes in the pulmonary vessels underlie pulmonary hypertension. The mechanism of formation of right ventricular hypertrophy is due to increasing pulmonary hypertension [15].

As for the cardiovascular system, in the early period (in 2 groups), the differences between the indices of these 2 groups were insignificant and only since 2000 a clearly marked decrease has been observed in the percentage of morbidity among the highlander

Table 1. Respiratory functional disturbances in "highlander" and "plainsmen"liquidators

\begin{tabular}{l|l|l|l|l|l}
\hline liquidators & liquidators & VC & FEV1 & FEV/VC & FVC/FEV_PEV \\
\hline \multirow{2}{*}{ early period } & "highlanders" & $89,1 \pm 2,62$ & $80,9 \pm 4,2$ & $89,2 \pm 2,5$ & - \\
\cline { 2 - 6 } & "plainsmen" & $81,8 \pm 2,55 p<0,05$ & $67,3 \pm 5,23 p<0,05$ & $82,5 \pm 2,27 p<0,05$ & \\
\hline \multirow{2}{*}{ late period } & "highlanders" & $87,4 \pm 2,8$ & $90.7 \pm 3,69$ & $99,0 \pm 3,34$ & $12,8 \pm 6,22$ \\
\cline { 2 - 6 } & "plainsmen" & $90,09 \pm 2,2$ & $94,61 \pm 3,35$ & $103,27 \pm 2,76$ & $11,59 \pm 1,93$ \\
\hline
\end{tabular}

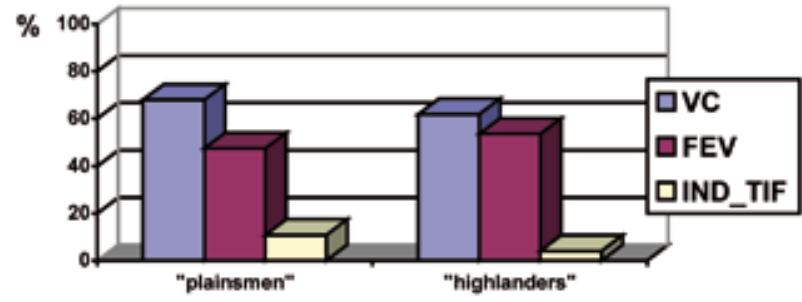

Early post-accident period

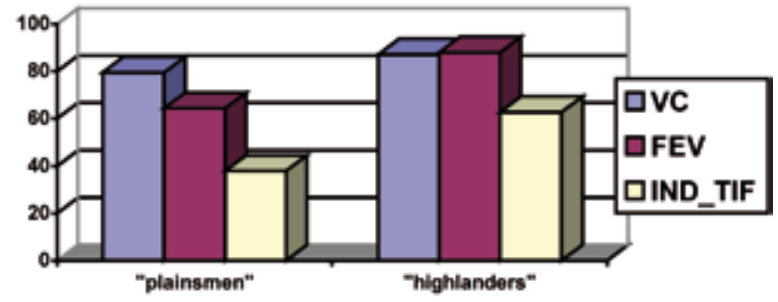

Late post-accident period

Fig. 2. Shares of influence of smoking on the indicators of the functional state of the respiratory system of "Iowland" and "high mountain" liquidators in the early and remote post-accident periods 
liquidators relative to the plainsmen. This can be explained by the fact that among the population of the mountaineers, atherosclerotic lesions of the main and peripheral vessels develop later and progress poorly. A smaller loss of elasticity of the vessels with age of the liquidators facilitates the work of the heart as well.

In liquidators who live in the highland regions of Armenia, significantly fewer cases of myocardial nutrition disorders (10.5\% relative to the plainsmen $29.1 \%)$, conduction disorders ( $5.3 \%$ relative to $7.6 \%$ ), and arrhythmias ( $5.3 \%$ relative to $21.5 \%$ ) have been revealed. The "highlanders" were also found to have a smaller number of such clinical cases as: myocardial infarction (in the highlander $5.3 \%$ relative to the plainsmen $-6.3 \%)$, heart failure (31.6\% relative to $40.5 \%)$ and ventricular hypertrophy (36.8\% relative $-39.2 \%)$. In permanent residents of highland areas, adaptive changes are formed at the tissue level. In particular, a number of authors $[11,15]$ indicate that in the highlanders, increased utilization of oxygen by tissues occurs as a result of increased vascularization and increased activity of tissue enzymes, and not due to the intensification of the blood flow and increased cardiac output. The presence of hypertrophy of the right ventricle of the heart in mountaineers is also noted as a decisive factor in the inclusion of the adaptive mechanisms of the body, in particular tissue factors. Of all cases of ventricular hypertrophy, in $68 \%$ of the highlander liquidators right ventricular hypertrophy has been observed.

Issues of the impact of mountain climatic factors on the human body in different age periods are not well understood. Revelation thereof is of interest for finding both theoretical and practical solutions to the prevention of premature aging. In permanent highland residents, the heart rate changes with age to bradycardia (found in $25.53 \%$ of highlanders relative to the plainsmen - 17.85\%). At the same time, in highlanders the time of the systolic segment is somewhat less, and the diastolic time is longer than that in the plainsmen. A significant difference was found in the mean systolic pressure of the liquidators living in hypoxia $((127,1 \pm 3,1)$ and the plainsmen liquidators $(138,2 \pm 4,12)$. According to Alipov D.A. [16], these phenomena in mountaineers can be considered as a characteristic adaptive response that provides better filling of the heart during diastole and more economical use of the heart muscle energy.

As it is known, constant life in high altitude conditions causes persistent adaptive red blood changes. According to the works of Mirrakhimov M.M. and co-authors [17], the total number of red blood cells can be $5 \%$ higher than that in the individuals living at sea level. We found no significant differences in the number of red blood cells in the plainsmen and bighlander liquidators, although there was a tendency to increase in this number, and there was a significant direct correlation relationship between the number of the red cells and hemoglobin level (in the early post-accident period $\mathrm{r}=0.63$ and in the late period $\mathrm{r}$ $=0.87$ ) in the highlander liquidators, throughout the period of the research. We have found a significant increase in the level of hemoglobin in the blood of the bighlanders $(164.5 \pm 1.12 \mathrm{~g} / \mathrm{l}$ - in the early period and $151.9 \pm 1.79 \mathrm{~g} / \mathrm{l}$ - in the remote period) relative to the "plainsmen" liquidators (in the early $-161.4 \pm 1.15 \mathrm{~g} / \mathrm{l}$, in the remote $-146.07 \pm 2.25 \mathrm{~g} / \mathrm{l}$ ), which is confirmed by the literature data [18], where this increase is associated with an increase in the oxygen capacity of the blood in the residents permanently living in the conditions of high altitude.

The results of the analysis of immunological indicators are presented in Table 2.

From the presented data, it can be seen that, in the early post-accident period, a significant difference was observed in T-lymphocytes (relative number $-29.71 \pm 2.16$ for highlanders and $36.67 \pm 1.5$ for plainsmen), and, in the long-term period, a significant difference was observed in almost all immunological parameters in the above-mentioned groups. In the highlanders in the long-term period, a decrease in the relative number of B-cells was revealed not only in relation to the plainsmen liquidators but also in comparison with the norm.

\section{CONCLUSIONS}

Thus, we have found that the morbidity rates by the following cardiovascular system and CNSLD, from 1995 to 2010 in highlander liquidators, were significantly lower compared to plainsmen liquidators, which indicates a presence of protective mechanisms in permanent residents of mountainous areas. In the early post-accident period, there was a significant difference between the indicators of lung function in groups I and II of liquidators.

Using the dispersion factor analysis, the shares of the influence of the radiation factor on $\mathrm{VC}$ and FEV (in the early $(50.57 \% ; 34.5 \%)$ and in the long-term $(20.21 \% ; 24.13 \%))$ and smoking (in the early $(64.87 \%$; $50.64 \%)$ and in the long-term periods (83.29\%;

$76.19 \%)$ ), which indicates that there is a decrease in the influence of radiation and an increase in non-radiation factors (age, smoking).

In the liquidators who live in highland regions of Armenia, significantly fewer clinical cases related to cardiovascular system, were found. In 68\% of the highlander liquidators, right ventricular hypertrophy was observed, which is an adaptive change for them. 
Table 2. Immunological indices in "plainsmen" and "highlander" liquidators in early and late post-accident periods.

\begin{tabular}{|c|c|c|c|c|c|c|c|c|c|c|c|}
\hline \multirow{2}{*}{\multicolumn{2}{|c|}{$\begin{array}{l}\text { liquidators, } \\
\text { period }\end{array}$}} & \multirow{3}{*}{$\begin{array}{l}\begin{array}{l}\text { T-Cells (rel) } \\
(\%)\end{array} \\
29,71 \pm 2,16\end{array}$} & \multirow{3}{*}{$\begin{array}{l}\begin{array}{l}\text { T- Cells (abs) } \\
\text { (uL) }\end{array} \\
988,91 \pm 104,9\end{array}$} & \multirow{3}{*}{$\begin{array}{l}\begin{array}{l}\text { B-Cells (rel) } \\
(\%)\end{array} \\
19,24 \pm 1,75\end{array}$} & \multirow{3}{*}{$\begin{array}{l}\text { B-Cells (abs) } \\
\text { (uL) } \\
650,86 \pm 80,02\end{array}$} & \multicolumn{2}{|l|}{ Phagocytosis } & \multirow{3}{*}{$\begin{array}{l}\text { Comple- } \\
\text { ment titer } \\
(\%) \\
36,59 \pm 1,1\end{array}$} & \multirow{3}{*}{$\begin{array}{l}\lg A \\
(\mathrm{~g} / \mathrm{L}) \\
1,51 \pm 0,13\end{array}$} & \multirow{3}{*}{\begin{tabular}{|l|}
$\lg G$ \\
$(\mathrm{~g} / \mathrm{L})$
\end{tabular}} & \multirow{3}{*}{ 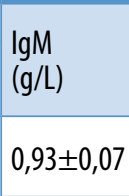 } \\
\hline & & & & & & \multirow{2}{*}{$\begin{array}{l}\% \\
49,28 \pm 1,58\end{array}$} & \multirow{2}{*}{$\begin{array}{l}\text { number } \\
4,09 \pm 0,14\end{array}$} & & & & \\
\hline \multirow{2}{*}{$\frac{\text { 은 }}{\text { 츨 }}$} & "highlanders" & & & & & & & & & & \\
\hline & "plainsmen" & $\begin{array}{l}36.67 \pm 1,5 \\
p<0.05\end{array}$ & $1143,2 \pm 84,78$ & $18,79 \pm 0,47$ & $561,52 \pm 18,74$ & $48,16 \pm 0,43$ & $4,02 \pm 0,09$ & $36,21 \pm 0,32$ & $1,69 \pm 0,03$ & $12,62 \pm 0,18$ & $0,96 \pm 0,02$ \\
\hline \multirow[b]{2}{*}{ 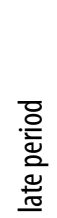 } & "highlanders" & $48.7 \pm 0,79$ & $841,2 \pm 76,54$ & $14.5 \pm 0.71$ & $362.33 \pm 66.38$ & $32.2 \pm 0.31$ & $12.2 \pm 0.2$ & $26.75 \pm 1.75$ & $2.4 \pm 0.2$ & $14.4 \pm 0.21$ & $1.8 \pm 0.1$ \\
\hline & "plainsmen" & $\begin{array}{l}37.4 \pm 0.6 \\
p<0.05\end{array}$ & $723.8 \pm 94.01$ & $\begin{array}{l}24.25 \pm 1.88 \\
p<0.05\end{array}$ & $\begin{array}{l}830.51 \pm 145.8 \\
p<0.05\end{array}$ & $\begin{array}{l}30.18 \pm 0.3 \\
p<0.05\end{array}$ & $\begin{array}{l}11.2 \pm 0.2 \\
p<0.05\end{array}$ & $29.1 \pm 2.1$ & $2.2 \pm 0.16$ & $\begin{array}{l}13.44 \pm 0.39 \\
p<0.05\end{array}$ & $1.74 \pm 0.07$ \\
\hline
\end{tabular}

Significant differences in RBC and immunological parameters between highlander and "plainsmen" liquidators were also recorded.

Thus, the liquidators living in conditions of hypoxia turned out to be more enduring to the conditions of ionizing radiation exposure. This is explained by the physiological adaptation that has arisen throughout the life in conditions of high mountains.

\section{REFERENCES}

1. Tatum S. Simonson Altitude Adaptation: A Glimpse Through Various Lenses, High Alt Med Biol. J., 2015, 16(2), p. 125-137

2. Dempsey J.A., Morgan B.J., Humans In Hypoxia: A Conspiracy of adaptation, Physiology, 2015, 30(4):, p. 304-316.

3. Muratov $\mathbf{Z H}$. K. The role of hypoxia in the development and course of acute mountain sickness, alpine hypoxia and human adaptation problems. Education and science in modern conditions, Interactive, 2015, 4 (5), p. 46-50 (rus)

4. Muratov ZH. K. The influence of high-mountainous factors on the human body. A new word in science: perspectives of development, materials VII Intern. scientific and practical conference, Cheboksary, CNS Interactive Plus, 2016, 1 (7), p. 129-133. (rus)

5. Lewis N.S., Bailey D.M., Dumanoir G.R., MesSunger L., LuCAS S.E., CotTer J.D., Donnelly J., Eneny J.M., Yong I.S., STenbridge M., BurGESS K.R., BASNet A.S., Aindlie P.N. Conduit artery structure and function in lowlanders and native highlanders: relationships with oxidative stress and role of sympathoexcitation., J. Physiol., 2014, 592(5), p. 1009-1024

6. Bigham A.W., LeE F.S. Human high-altitude adaptation: forward genetics meets the HIF pathway, Genes Dev.J., 2014, 28(20), p. 2189-2204

7. Cheong H.I., Janocha A.J., Monocelb L.T., Garchar A.C., Gebremedhin A., Erzurum
S.C., BEALl C.M. Alternative hematological and vascular adaptive responses to high-altitude hypoxia in East African highlanders, Am J Physiol Lung Cell Mol Physiol., 2017, 312(2), p.172-177

8. Pham L.V., Meinzen Ch., Arias R.S., Schwartz N.G., Rattner A., Miele C.H., SMith P.L., SCHneider H., Miranda J.J., Gilman R.H., PolotSKY V.Y., CheCKLEY W., SCHWARTZ A.R. CrossSectional Comparison of Sleep-Disordered Breathing in Native Peruvian Highlanders and Lowlanders. High Alt Med Biol., 2017, 18(1), p.11-19

9. Horscroft J.A., Kotwica A.O., Laner V., West J.A., Hennis P.J., Levett D.Z., Howard D.J., Fernandez B.O., Burgess S.L., Ament Z., Gilbert-Kawai E.T., Vercueil A., Landis B.D., Mitchell K., Mythen M.G., Branco C., JOHNSON R.S., FEELISCH M., MONTGOMERY H.E., Griffin J.L., Grocott M.P., GNaiger E., MARTIN D.S., MurraY A.J. Metabolic basis to Sherpa altitude adaptation. Proc Natl Acad Sci USA, 2017, $114(24)$, p. 6382-6387

10. Bhattarai P., Paudel B.H., Thakur D., Bhattarai B., Subedi B., Khadka R. Effect of long term high altitude exposure on cardiovascular autonomic adjustment during rest and post-exercise recovery. Ann Occup Environ Med., 2018, p. 30-34

11. Matthew E. Pamenter and Frank L. Powell. Time Domains of the Hypoxic Ventilatory Response and Their Molecular Basis. Compr Physiol, 2016, 6(3), p. 1345-1385.

12. Kuznetsova VK, Lyubimov GA, Kamenev M.Yu. Dynamics of resistance to air flow during the phase of its increase in the process of forced exhalation with various violations of breathing mechanics. J. Pulmonology, 1995, 4, p. 36-41 (rus)

13. VukoLov E.A. Fundamentals of statistical analysis. Workshop on statistical methods and investigation of operations using STATISTICA and EXCEL packages, Moscow, Forum. 2008, (rus) 
14. BurEeVA N.N. Multidimensional statistical analysis with use of a package of applied programs STATISTICA, Bottom Novgorod: NNGU, 2007, - 112p. (rus)

15. Dotdaeva A.A., Kurdanov Kh.A., Boytsov S.A. Morbidity and mortality from cardiovascular diseases, depending on the height of the region above sea level. Cardiovascular therapy and prevention, 2016, 13 (6), p. 51-55. (rus)

16. Alipov D.A. Human adaptation in various climaticgeographical and production conditions, 3 International Conference. Ashgabat, 1981,.4, p.160-161 (rus)

17. Mirrakhimov M.M., Yusupova N. Ya., RaimzhANOV A. R. The significance of red blood in the adaptation of the human body to high altitude conditions. Mountains and the blood system, Frunze, 1969,. 56, p. 77-78. (rus)

18. TкaChenko B.I. Normal human physiology, Medicine, 2005, - 909p. (rus) 